\title{
Puestos fronterizos,
}

guardias, fortines $y$

fuertes de la frontera

rioplatense tardocolonial: entre la polisemia y las carencias castrenses

Frontier Posts, Guards, Small Forts and Forts of the Late-Colonial River Plate Border: Between Polysemy and Military Deficiencies

DOI: https://doi.org/10.22380/20274688.1778

Recibido: 12 de enero del 2021

Aprobado: 22 de febrero del 2021
ARNALDO ANDRÉS AGUIRRE*

Universidad Nacional de Luján, Argentina

aguirreandres@hotmail.com.ar

EDUARDO IRAOLA**

Universidad Nacional de Luján, Argentina profeduardoiraola@gmail.com

\section{R E S U M E N}

En la denominada frontera sur de América genas y las hispanocriollas que practicaron del Sur convergieron las poblaciones indí- $\quad$ una serie de estrategias defensivas. Un

* Profesor en Historia, Universidad Nacional de Luján (UNLu), Luján, Provincia de Buenos Aires, Argentina; doctor en Antropología, Universidad de Buenos Aires (UBA), Buenos Aires, Argentina, https://orcid.org/0000-0002-0027-6520. Docente de la Universidad Nacional de Luján, integrante del Programa de Estudios Históricos Antropológicos Americanos, investigador categoría v.

** Profesor en Historia, Universidad Nacional de Luján (UNLu), Luján, Provincia de Buenos Aires, Argentina; doctor en Ciencias Sociales, UNLu, https://orcid.org/0000-0002-6082-5579. Docente de la Universidad Nacional de Luján (jefe de trabajos prácticos) y de la Universidad Nacional de la Patagonia Austral (profesor adjunto), integrante del Programa de Estudios Históricos Antropológicos Americanos. 
conjunto variable de edificaciones militares se fue extendiendo entre la Banda Oriental del Uruguay (actual República Oriental del Uruguay) y Buenos Aires (Argentina), que se encontraban en una misma jurisdicción administrativa. Si bien estas estructuras castrenses compartieron las propias denominaciones de la corporación, no obstante, los aspectos constructivos pusieron en evidencia notorias diferencias. Los puestos fronterizos, guardias, fortines y fuertes distribuidos en la jurisdicción supusieron diferencias de dotación, aunque con más sutileza preservaron una importante polifonía. La historiografía clásica tendió a estudiar estas guarniciones de modo literal otorgando a cada estructura militar las características que implicaban su nominación, mientras que artículos más recientes, que problematizan estas propuestas, contribuyen a interpelar la materialidad de esas tipologías militares al mostrar cómo en numerosas oportunidades no llegaban ni la dotación de soldados ni la de artillería, al tiempo que la edificación únicamente existía en los planos. El objetivo de este artículo es, por una parte, presentar una primera indagación de carácter comparativo en torno a las denominaciones constructivas militares a ambos lados del Río de la Plata. Por otra parte, apuntamos a contraponer el empleo de dichas denominaciones y la materialidad expresada en los fondos documentales.

Palabras clave: Banda Oriental, Río de la Plata, Buenos Aires, fortificaciones, sistema defensivo

\section{$\begin{array}{llllllll}\mathbf{A} & \mathbf{B} & \mathbf{S} & \mathbf{T} & \mathbf{R} & \mathbf{A} & \mathbf{C} & \mathbf{T}\end{array}$}

The south frontier of South American converged the indigenous people and the Hispanic-creoles that performed a series of defensive strategies. A variable set of military settlements was extended between Banda Oriental (current República Oriental del Uruguay) and Buenos Aires (Argentina) that were in the same administrative jurisdiction. Even though, these military structures shared the own denominations of the corporation, however the constructive aspects provide evidence of notorious differences. The frontier posts, guards, small forts and forts that were distributed in the jurisdiction implied differences in the military strengths though with more subtlety preserved an important polyphony. The classic histo- riography tended to study these garrisons in a literal way giving each military structure the characteristics that implied its nomination, while more recent papers problematize these proposals and provided in questioning the materiality of those military typologies by putting in evidence that in numerous opportunities the military strengths neither the artillery arrived, at the same time, the edification only existed in the planes. On one hand, the purpose of the paper is to present a first comparative inquiry towards the military constructive denominations on both sides of Rio de la Plata. On the other hand, we aim to oppose the use of those denominations and the materiality expressed in the documentary collections.

Keywords: Banda Oriental, Rio de la Plata, Buenos Aires, fortifications, defensive system 


\section{Introducción}

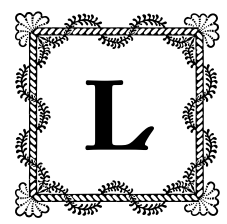

a historiografía colonial clásica tendió a estudiar la defensa de la frontera $\operatorname{sur}^{\mathrm{I}}$ como un límite en el que recaían específicamente actividades militares (Barros; Beverina; Cabodi; Raone; Pérez), mientras que estudios más recientes apuntan a propuestas relacionales desde la nueva historia política, sostenidas en variables del poder local (Mayo y Latrubesse; Néspolo, "Cautivos"). En las primeras, las estructuras militares eran meras construcciones defensivas con exiguas descripciones y carentes de análisis, mientras que en la segunda aparecen como depositarios de fuerzas militares y constituyendo el espacio potencial de relaciones sociales. Únicamente Néspolo ("Resistencia”) propone una separación en términos de estructura y de fuerzas destinadas, sin indagar en las características constructivas ${ }^{2}$. Sin embargo, un relevamiento más amplio del material documental y una propuesta de estudio comparativo permiten el hallazgo de diferencias edilicias, además de un entramado polisémico en torno a las categorías de fuerte, guardia y puesto.

El Diccionario de Covarrubias define fuerte como "la fortaleza, o sitio fortificado, que puede resistir a los enemigos" (I9 r.) aunque, como veremos, en el Río de la Plata, a veces, este apelativo estuvo más ligado a la dotación de tropas que a la estructura edilicia, mientras que dicho repertorio delimita guardia como "las que se ponen en los puertos, y en las puertas de las ciudades, y en las casas, o fortalezas donde están presos a consideración” (43 r.). De tal manera, la acepción se acota a los sujetos y no a un tipo de edificación militar. Finalmente, la palabra puesto se refiere a "Campo o lugar ocupado por tropa o individuos de ella o de la policía en actos del servicio" (RAE). La imprecisión de estas tres palabras permitió un uso indistinto de ellas por los sujetos de la época, mientras que la historiografía contemporánea tiende a interpretarlos como tipologías fijas.

La movilidad de las parcialidades indígenas y la necesaria condición provisional del espacio ocupado, debido al anhelo de la conquista completa,

I La frontera sur de América del Sur fue el área comprendida por la línea militar extendida desde el río Yi (Uruguay), la línea del río Salado, el camino a Cuyo (Argentina), concluyendo en el río Biobío (Chile) (Tamagnini; Pérez).

2 Referidas a tipos y orígenes de los materiales, dimensiones y organización edilicias, durabilidad, entre otros. 
suponían que las estructuras militares debieran adaptarse a la propia estrategia de ocupación o invasión. De este modo, en un proceso arduamente lento, las poblaciones hispanocriollas fueron desgastando las resistencias indígenas, como en una invasión silenciosa que no dejaba de poseer coyunturas de mayor beligerancia que acababan en una avanzada territorial, aunque la presencia de una serie de malones disciplinaría a los hispanocriollos a sus espacios consolidados.

De este modo, el frente poblacional generaba fricciones, avances y retrocesos, en una estrategia de hormiga que se manifestó en una combinación de ataque y pacificación. Mientras dicho frente avanzaba, detrás quedaba un territorio cada vez más consolidado, y ello requería una defensa cada vez más sólida. Finalmente, estaba el espacio hispánico indiscutido: la ciudad. En este caso, el enemigo tenía otras características en concreto, era europeo y los ataques marítimos, por lo que la estrategia defensiva debía, necesariamente, ser distinta. Por ello, una serie de fortificaciones de considerable solidez coronaban el Atlántico frente a las incursiones de varias naciones europeas y en particular de la amenazante Corona portuguesa.

En ambas márgenes del río de la Plata — tanto la de Buenos Aires como la Banda Oriental ${ }^{3}$ - durante el siglo XviII, la presencia de fuertes, fortines, guardias y puestos de frontera registró el conflicto entre indígenas e hispanocriollos, indígenas y lusitanos, así como lusobrasileños y españoles, además de intercambios económicos y negociaciones de paz, entre otros. La prolongada existencia de estos espacios de interacción y relaciones interétnicas exigió a las autoridades políticas, los pobladores hispanos y los indígenas innovar métodos para lograr sus objetivos de ocupación, defensa y control de los distintos espacios disputados entre las sociedades en contacto.

La Banda Oriental del Uruguay se fue configurando como un espacio de múltiples frentes de conflictos y de negociaciones. Por un lado, como frontera interna, es decir, la habitual separación dentro del propio "espacio" de los asentamientos hispanocriollos urbanos o rurales, del de los indígenas no reducidos, que mayormente se encontraban al noroeste de las jurisdicciones de Montevideo y Maldonado, lugar hacia donde se dirigía paulatinamente la población de origen europeo apoyada por el establecimiento de guardias y fortines en los bordes de

3 La Banda Oriental era la jurisdicción colonial ubicaba al este del río Uruguay y al norte del río de la Plata, sobre la costa atlántica de Sudamérica, y ocupaba, aproximadamente, el espacio de la actual República Oriental del Uruguay y el sur de Brasil. 
la jurisdicción (Aguirre). Por otro lado, lo que denominamos "frontera externa", por su particular ubicación geográfica entre los imperios coloniales lusitano y castellano, que desde el siglo XviI comenzaron a luchar por la ocupación y el control, en tanto que la frontera bonaerense quedó comprendida, a partir de I780, por la línea de fortines establecida por el asentamiento de los pobladores hispanocriollos y la limitación natural del río Salado al sur de la campaña (Néspolo, "Resistencia").

Hacia fines del periodo colonial, el Río de la Plata se caracterizó por la necesidad de responder paralelamente a diferentes amenazas: por un lado, la protección del acecho de piratas, corsarios y potencias extranjeras (Gran Bretaña, Francia, entre otros); por otro lado, garantizar la seguridad de la "frontera interior" contra las incursiones de los indígenas no reducidos de Pampa y Patagonia (Néspolo "Resistencia"; Nacuzzi; Canedo); y por último, la defensa de la frontera con los portugueses en Moxos, Chiquitos y la Banda Oriental. En esta última se desarrolló una estrategia de despliegue de fuerzas terrestres y una red de fortificaciones (Santa Teresa, San Miguel y Santa Tecla) junto a los poblados defensivos. Esta "militarización" de la frontera hispanoportuguesa constituyó el principal incentivo para la reestructuración militar del área rioplatense $e^{4}$.

Toda esta estrategia militar y geopolítica supuso un tiempo considerable de relaciones sociales que permitieron consolidar vínculos que sedimentaban las prácticas mientras podían retrasar el avance. Claramente, un ataque frontal al espacio indígena suponía la ruptura de toda una serie de pactos escritos e implícitos que debían ser reajustados por el temor a la respuesta indígena. Por ello, la frontera emergió como un espacio políticamente concertado que pudo también limitar el avance (Aguirre; Néspolo, "Cautivos").

De este modo, las estructuras militares se convirtieron en espacios de encuentro y conflicto, sin embargo, dichos espacios poseyeron características constructivas que estaban estrechamente vinculadas a un momento determinado

4 La palabra "militarización" para el Río de la Plata se utilizó de manera polisémica por parte de los investigadores dedicados al tema (Halperín, Militarización y Revolución y guerra; Garavaglia; Fradkin, entre otros). Entendemos militarización como la movilización masiva, cada vez más importante e inclusiva, de la población masculina en el seno de unidades militares. En este sentido, el adjetivo no apela a la definición que indica: "la acción y efecto de militarizar", en tanto esta (militarizar) se define como: "Inculcar la disciplina o el espíritu militar// Someter a la disciplina militar a personas o agrupaciones civiles// Dar carácter u organización militar a una colectividad” (Diccionario Enciclopédico, 1994). 
en esa historicidad y que respondieron a fines prácticos y estratégicos. La propuesta general del presente trabajo es reconocer algunas de esas características de las estructuras militares de campaña en el espacio rioplatense como un primer aporte al estudio de sus funciones, conflictos y necesidades. En ese sentido, en un primer momento ofreceremos los puntos comunes de los fuertes y los fortines, para luego avanzar sobre las guardias y los puestos militares. Finalmente, ofreceremos un balance que permita comprender de manera más certera los pormenores del control del espacio, así como las estrategias militares para su ocupación y consolidación.

\section{Sobre fortificaciones, fuertes y fortines: piedras, adobes, artillería y dotación de tropa}

En la segunda mitad del siglo XviII, dentro de la jurisdicción del Río de la Plata, las plazas fuertes eran Buenos Aires, Montevideo y Maldonado. La primera era la sede de la gobernación y luego la capital del virreinato; la segunda fue elevada a plaza de armas y gobierno político-militar, con la misión de resguardar la seguridad de las posesiones españolas al este del río de la Plata y en todo el Atlántico sur'; mientras que Maldonado, por su cercanía a las posesiones portuguesas, se constituyó en un punto militar fuerte de la región; allí se instaló un gran cuartel de dragones para seiscientos soldados, un conjunto de baterías y torres de vigía, todas ellas fortificadas y defendidas por el ejército de dotación y el de refuerzo, enviados en diferentes compañías directamente desde la metrópolis, auxiliadas con milicias locales (Marchena 72). Claramente, la acepción de "sitio fortificado" es la más acorde en consonancia con la asociación de fuerte y dotación militar.

5 Montevideo fue una ciudadela amurallada, por su importancia estratégica y porque su bahía constituye un puerto natural donde fondear naves de ultramar e invadirla. En cambio, Buenos Aires, aunque tenía el fuerte, era más difícil de tomarla con un desembarco porque no constituye un puerto natural. 


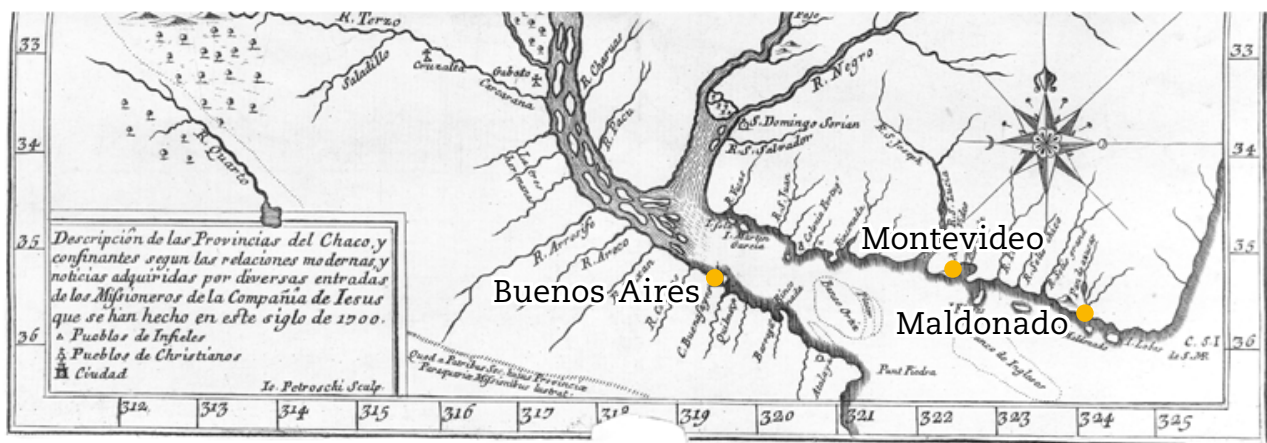

$\leftrightarrow$ FIGURA I.

“Descripción de las Provincias del Chaco, y confinantes según la relaciones modernas, y noticias adquiridas por diversas entradas de los Misioneros de la Compañía de Jesús que se han hecho en este siglo de I700"

Fuente: Pedro Lozano, Descripcion chorographica del terreno, rios, arboles y Animales de las dilatadifsimas Provincias del gran Chaco, Gualamba: y de los ritos, y costumbres de las innumerables Naciones barbaras, è infieles, que le habitan: con una cabal relacion historica de lo que en ellas han obrado para conquiftarlas algunos Governadores, y Miniftros Reales: y los Miffioneros Jefuitas para reducirlos à la Fé del verdadero Dios. Córdoba: Colegio de la Assumpcion, por Joseph Santos Balbàs, I733. Colección de la Biblioteca de la Universidad de Sevilla. https://archive.org/details/AI52024/ page/n3/mode/2up

La Banda Oriental, en particular, fue adquiriendo una posición geopolítica fundamental en este periodo por ser una zona fronteriza "interimperial" entre las posesiones portuguesas y espańolas. Este espacio de frontera colonial, con las características propias de una región periférica (respecto de Buenos Aires, Montevideo u otros centros de mayor relevancia $)^{6}$, devino en frontera interétnica porque confluían en este sociedades distintas: las indígenas (minuanos, charrúas y tapes-guaraníes) y las europeas. Sin embargo, la singularidad del espacio de frontera en la Banda Oriental residió en el tipo de fortificaciones militares que se alzaron en el litoral atlántico. Si, por un lado, los emplazamientos militares de campaña que se erigieron en la "frontera con el indio" eran los característicos de este tipo de fronteras en el siglo XvirI: de madera, "palo a pique", transitorias y con espacio para unos pocos hombres — que analizaremos más adelante-, por otro lado, las fortificaciones militares abaluartadas que se erigieron sobre el litoral atlántico respondieron a las necesidades geoestratégicas de la Corona española en la cuenca del río de la Plata.

6 Sobre estudios comparativos respecto de la configuración de espacios de fronteras coloniales en las periferias imperiales véase Gascón. 
Estos emplazamientos militares que se levantaron en la Banda Oriental, como en toda la América española, eran parte relevante de la estrategia defensiva y tenían sus características propias. Seguían las líneas generales del sistema Vauban 7 , quien concibió fortificaciones de relativamente poca altura y muy resistentes al fuego de artillería. Los vértices de estos fuertes estaban defendidos por baluartes artillados, mientras que los bastiones se protegían entre sí, al tiempo que podían cruzar sus fuegos (véase figura 2), a su vez, se encontraban unidos por un muro de piedra denominado cortina (Luzuriaga, "El sistema defensivo" 2).

En este sentido, los fuertes de Santa Teresa y San Miguel ocuparon un lugar central por hallarse en el camino conocido como Castillos Grandes o la Angostura del Chuy, sobre el océano Atlántico. Este era uno de los pasajes obligados para trasladarse entre la Banda Oriental y el Río Grande en el sur de Brasil, sobre todo si se pretendía movilizarse por carretas o pertrechos militares. Por su parte, el de Santa Tecla se hallaba en otro de los lugares estratégicos para la defensa del territorio, el de la Cuchilla Grande en las nacientes del río Negro, puerta de entrada a los pueblos de las misiones jesuíticas que se hallaban al oriente del río Uruguay, y a las demás jurisdicciones de la Banda Oriental.

Inicialmente, el fuerte de San Miguel fue construido por los portugueses alrededor de 1737, entre la margen izquierda del arroyo San Miguel y el sur de la laguna Mirim. Ese año, el gobernador de Río de Janeiro, Gomes Freire de Andrade, mandó levantar fortificaciones en Río Grande y la región circundante, que le pudieran servir de enlace terrestre con Colonia del Sacramento. En cumplimiento de esa orden se erigieron tres fuertes: el de Jesús, María y José, en lo que hoy es la barra de Río Grande; el de Santa Ana, unos kilómetros hacia el interior, y el de San Miguel, en las proximidades del arroyo del mismo nombre. Este último se construyó con tepes - tierra apisonada - y abarcaba una superficie de tres mil metros cuadrados. Posteriormente fue reedificado, en su ubicación actual, y según la documentación "con piedra seca”. Hacia 1740 ya tenía su configuración definitiva, de acuerdo con el sistema Vauban. Con un perímetro de $300 \mathrm{~m}$, y a $35 \mathrm{~m} \mathrm{s.} \mathrm{n.} \mathrm{m.,}$ estaba destinado a proteger y vigilar el paso conocido como la Angostura. Para 1763, luego de ser tomado por el gobernador Cevallos, contaba con la presencia de casi un centenar de hombres y tenía seis cañones (AGN, BO-FST, IX-I5-8-2).

7 El nombre alude al ingeniero militar francés Sebastián Le Presté, señor de Vaubán (1633-1707), quien en el siglo XVII había estudiado cómo construir obras defensivas eficaces ante las armas de fuego y, a su vez, cómo asediar y tomar tales fortificaciones. 
La fortaleza de Santa Teresa era la más grande de este conjunto de construcciones defensivas y, al igual que San Miguel, fue iniciada por los portugueses en 1762, pero conquistada y concluida por los españoles luego de 1763. Se trataba de un pentágono irregular, cuyo lado exterior más grande medía I5I varas —unos $126 \mathrm{~m}$ - Fue construida totalmente en piedra, con arena y cal. Sus muros llegaban a tener entre io y ir $\mathrm{m}$ de espesor, con sus rellenos en la parte baja, y hasta casi $2 \mathrm{~m}$ en los parapetos que contorneaban la traza inicial del pentágono, con cinco baluartes que se adaptaban al relieve del terreno y miraban a los puntos estratégicos (Luzuriaga, "El sistema defensivo" 3).

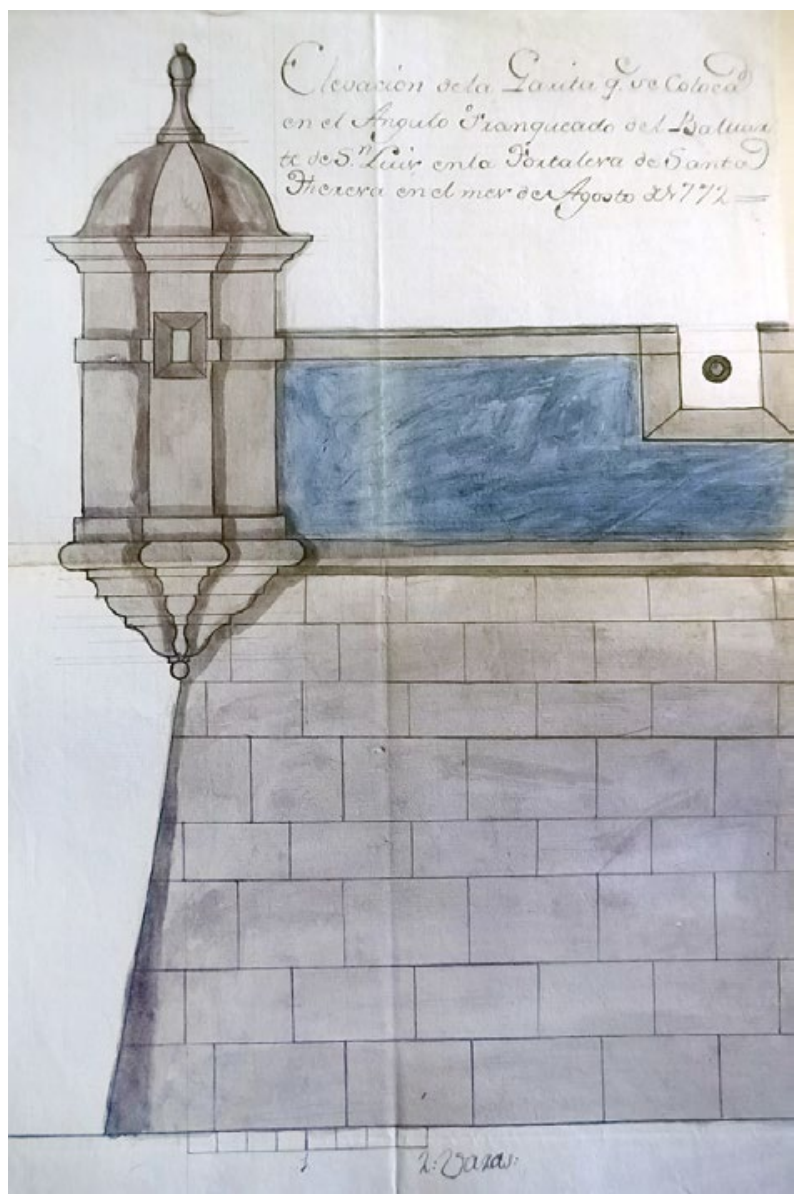

$\rightarrow$ FIGURA 2 .

Garita elevada, ángulo flanqueado del baluarte de San Luis, fortaleza de Santa Teresa. Ingeniero Bernardo Leqoc, Agosto de 1772

Fuente: AGN, BO-FST, IX-I5-8-2. 
La construcción en piedra de Santa Teresa fue sumamente costosa, en su recinto se albergaba el cuartel de la tropa, la capilla y las casas de autoridades y oficiales. La importancia del fuerte Teresa radicaba en el control del paso de la Angostura, que unía a Montevideo y Maldonado con la frontera portuguesa y servía de antemural, aunque tenía como avanzada a unos $30 \mathrm{~km}$ el fuerte de San Miguel. La localización era perfecta en la medida en que, más allá de su carácter dominante, el territorio de esteros, lagunas y dunas hacia la costa, hacía de Santa Teresa un punto de paso obligado para el desplazamiento de tropas (Gutiérrez 360).

En relación con el personal que guarnecía la fortaleza, es difícil determinarlo, dado que podía variar conforme se sucedían los tiempos de guerra y de paz. Si para los tiempos de paz, el piloto de la Real Armada Andrés Oyarvide manifestó que bastaba con una tropa de 50 soldados y sus oficiales, en tiempos de guerra hemos llegado a contabilizar hasta 455 hombres de la compañía de Dragones de Buenos Aires, a los que habría que sumarles los blandengues ${ }^{8}$ y milicias de diferentes ciudades (AGN, BO-FST, IX-I5-8-I, 3I de octubre de I776).

Santa Tecla fue el último, y el más efímero, de estos emplazamientos militares que los españoles construyeron en la Banda Oriental. En noviembre de $\mathbf{1 7 7 3}$, el gobernador de Buenos Aires, Juan José de Vértiz, decidió enfrentar los movimientos de los portugueses, que intentaban recuperar Río Grande, y en campaña ordenó construir Santa Tecla ${ }^{9}$. A tal fin comisionó al ingeniero Bernardo Lecocq, para erigir un fuerte tipo Vauban, con foso, rastrillo y cinco baluartes. Este sería similar al de Santa Teresa pero de dimensiones reducidas, con capilla, pabellón de oficiales, cuartel de tropa, hospital y almacenes (Luzuriaga, "Campañas" 9).

En las guerras guaraníticas de 1754-1756, el marqués de Valdelirios reconoció su ubicación como estratégica, ya que se encontraba en una elevación prominente, formando una suerte de entrada por la sierra Cuchilla Grande, entre las nacientes de los ríos Negro y el Pirai Mini. Así, podía ser defendido desde las alturas y se tornaba dificultoso su asedio por agua. Esta locación resultaba ser la "puerta de entrada" a los diferentes puntos estratégicos de la Banda Oriental

8 En I751 se crearon como unidad de milicia de caballería ligera a sueldo, y desde 1784 tuvieron grado de fuerza veterana.

9 La villa de Río Grande de San Pedro y todo el espacio adyacente a la laguna de los Patos fueron conquistados por el gobernador de Buenos Aires, Pedro de Cevallos, en 1763 y sostenidos por las armas españolas hasta 1777, cuando fueron recuperados por los lusobrasileños. 
(las Misiones Orientales, Montevideo, Maldonado, Colonia del Sacramento), así como el acceso al lugar de mayor concentración de la riqueza ganadera, lugar desde donde se aprovisionaban los pueblos misioneros, puestos y fuertes desde Maldonado a Río Grande, e incluso en el interior de Brasil.

Este tipo de construcciones no fueron la norma en la frontera rioplatense, sino más bien la excepción, por los recursos económicos e incluso de logística que suponía su erección. A diferencia de la Banda Oriental, el litoral de Buenos Aires carecía de piedras, por lo que su fuerte estaba erigido esencialmente en ladrillos de adobe cocidos al sol. Dicha estructura militar se encontraba de frente al río de la Plata y a la vez expuesta al daño de las crecientes y las mareas, por lo que se debieron llevar a cabo repetidas reparaciones. La descripción del inglés Gillespie resulta bastante ilustrativa en este sentido:

[...] la gran plaza de armas, teniendo en la misma esquina el cabildo; y casi enfrente está el fuerte, que en nuestro tiempo era una defensa miserable para ciudad tan importante. Los cañones estaban picados, sus cureñas podridas, las murallas bajas y parcialmente demolidas hacia la plaza y el foso lleno de escombros, además de un puente levadizo; adentro, el castillo donde residía el gobernador y una capilla para él y sus acompañantes. (Gillespie 63)

El deterioro descripto se encuentra asociado a las características constructivas de adobes secados al sol. Ello implica que los materiales utilizados en Buenos Aires distan de los propios en la Banda Oriental aunque se preserve el diseño estructural de tipo estrellado con baluarte.

Si bien, esta imagen pudiera reducirse a la asociación de murallones de adobe cosido al sol y los efectos dañinos de las mareas del río, no obstante, existen similitudes considerables en las descripciones que el mismo prisionero hiciera sobre el fortín de Areco y luego sobre el fuerte de Salto. En cuanto al primero, menciona que "está construido de adobes [...] y tiene forma de estrella” (Gillespie I24), mientras que del fuerte de Salto dirá:

mucho más grande que el fortín de Areco, con dos de sus frentes levantados con tierra endurecida sacada del lecho del río y los otros protegidos por un foso y palizadas. Once cañones de hierro y pedreros estaban emplazados, en estado ruinoso, y había cuarteles anexos en condición análoga. La fuerza militar destinada a su defensa, si efectiva, consistía en un capitán primero y otro segundo, con cincuenta hombres que siempre eran criollos. (Gillespie I26) 
Los adobes cocidos al sol constituyen el sostén de los muros en los fuertes de la frontera de Buenos Aires. En Chascomús, dicha estructura defensiva se construyó en 1784 con el trabajo de presidiarios (AGN, CGF; IX-I-7-4, 7 de julio de I784) con alrededor de 20000 adobes (AGN, CGF; IX-I-7-4, I8 de diciembre de I784) y posee un foso perimetral que debe ser mantenido periódicamente. En I766, Joseph Linares al recibir la comandancia del fuerte de Arrecifes, expresaba:

este fuerte con sus tres turras [sic] de Piedra sin adicion, sur Leste y poniente, su norte de palo a pique que se compone de ciento quarenta y ocho palos todos de ńandu Bay, su frente de este dho con su esplanada su puerta, con alones y arranques $\mathrm{p}^{\mathrm{a}}$ Torrion su escalera para el dho su Cuerpo de Guardia algo maltratado desecho y su puerta de cuero, todo de piedra [...] (AGN, CGF; IX-I-5-2, II de diciembre de I766)

En los fuertes de la frontera bonaerense no solo se destacan los adobes como elemento constructivo, sino que la madera tiene una presencia notoria. No obstante, en este caso resalta la utilización de piedras sobre un lado, combinadas con palos sobre el otro lado. Si, por una parte, las características constructivas ponen en evidencia las posibilidades ofrecidas por el espacio en la elección entre piedras y adobes, por otro lado, sobresale la considerable inversión en dinero en la Banda Oriental. El mismo oficial describe sucintamente el estado de otro fuerte:

el Fuerte del Pergamino con sus quatro lienzos de tapial, y sus quarteles de lo mismo, yden estos quarteles destechados en un todo, sus maderas Catorce horcones Principales, siete Cumbreras todas de sauce, y sus orcones a pique formación de los lados de sus quarteles con la bivienda de los Oficiales con quarenta y nueva de la especie de los Principales, sus soleras, doze todas de sauce. Diez y nueve Tixeras de Sauce. (AGN, CGF; IX-I-5-2, II de diciembre de I766)

La omisión de los materiales que componen los "lienzos de tapial” permite suponer el uso de adobes ya que la obviedad está en la costumbre. El resto de la estructura se basa en la utilización de maderas y palo a pique, aunque, cabe destacar que en el caso de Arrecifes los palos son de ñandubay, una madera menos putrescible y más dura que el sauce (Iraola, "Que no es servicio"). Ahora bien, del mismo modo en que evidenciamos los problemas en estos fuertes bonaerenses, al ser levantados en adobe y madera en una región con altos promedios de lluvias al año, debemos decir que los informes de los testigos de la época dan por correcta esta estrategia. En palabras de Joseph Vague “[...] creeré sea el 
mas comodo, y mas durable, de todos los Fortines, por ser todas las viviendas y baluartes de adobe" (AGN, CGF, IX-I-4-I, I7 de junio de I78I). Claramente, dicho fortín preservaba la estructura de los anteriores, en cuanto poseía los baluartes en los extremos de una figura cuadrangular, algo que también se puede observar, aun siendo estructuras distintas, en el fuerte de El Zanjón.

El comandante, al tomar posesión del fuerte de El Zanjón, lo describirá del siguiente modo:

un quadrilongo de cincuenta y Siete bar ${ }^{\mathrm{s}}$ de largo defendido de Palo a Pique con Mil Postes de Yandubay sin Foso Ni Rastrillo ni Puerta, un quartel capaz para aloxar cinq ${ }^{\text {ta }}$ hom $^{\mathrm{s}} \mathrm{y}$ otro $\mathrm{q}^{\mathrm{e}}$ sirbe de piquete a la entrada del fuerte, otros dos que sirben de Capilla y havitazon a los Ofi ${ }^{\mathrm{s}} \mathrm{y}$ dos cosinas.

Dos corrales con trescienta y ochenta postes de Yandubay Un cepo sin candado (AGN, CGF, IX-I-5-3, 3 de febrero de I777)

La noticia dejada por Pedro Escribano permite reconocer que la designación de fuerte no se encuentra estrechamente ligada a las características constructivas: materiales, dimensiones y durabilidad. De hecho, los detalles que se observan en los extremos del plano del fuerte de El Zanjón son los lugares en los que se encuentran dispuestos los pedreros, aunque en ningún momento dicho comandante menciona la existencia de baluartes para ello. De manera similar, podremos evidenciar que este fuerte dista ostensiblemente de la condición de fortaleza o de una suficiente dotación militar, como se expresa en la definición que ofrecimos al inicio.

De este modo, podemos introducirnos en las problemáticas sobre la polisemia de estos términos, debido a que, del mismo modo en que este fuerte no comparte las características constructivas, el propio Pedro Escribano pone un membrete muy particular al informe de lo recibido, en concreto: "Participa haverse recivido de aquella guardia: Propone aumentar el Fuerte [...]” (AGN, CGF, IX-I-5-3, 3 de febrero de I777). Entonces, para los sujetos de la época, la diferencia entre guardia y fuerte no es tan tajante ni tan necesaria. Ello permite evidenciar que la historiografía estereotipó las palabras fuertes, fortines y guardias como tipologías fijas, adjudicándoles características particulares, cuando en realidad fueron mucho más dinámicas y heterogéneas. Las guardias se mencionan en la multiplicidad de su acepción, esto es, como acción, espacio y sinónimo de fuerte. 


\section{Guardias y puestos de avanzada: estructuras defensivas sin resolver}

La extensión de la frontera sur implicaba grandes dimensiones de tierra con pocos asentamientos hispanocriollos y una circulación autárquica de grupos indígenas. La ambición de conquistar la totalidad de los territorios existentes requería también poder hacer efectiva su ocupación. El conjunto de estas variables y un presupuesto reducido implicó la construcción de unas estructuras militares que la historiografía limitó a la descripción de "palo a pique", aunque extendió esta característica a todas las "guardias" o "puestos", sin reparar en dos cuestiones esenciales: por una parte, la necesaria movilidad/corrimiento de dicha estructura defensiva, y por otra, la polisemia de la palabra guardia.

En principio, una de las guardias más antiguas en Buenos Aires es la del río Luján (I663), que se ha trasladado en reiteradas ocasiones (Néspolo, "Resistencia" 296-307). Dicha movilidad aparece también en la guardia del río Las Conchas cuando Francisco Espinama denuncia las cosas que suceden en el "sitio donde $[\mathrm{h}]$ an tenido anteriormente su casa los Comandantes que todo se halla en la actualidad despoblado, por cuia causa es el albergue de muchas maldades" (AGN, CGF, IX, I-7-3, 2 de septiembre de I796), lo que fray Domingo Pérez certifica declarando:

dándome denuncia como en la Guard ${ }^{\mathrm{a}}$ vieja $\mathrm{q}^{\mathrm{e}}$ sirvió de havitac ${ }^{\mathrm{n}}$ a los $\mathrm{Com}^{\text {tes }}$ por la masiega y rancho ya deteriorado se seguían graves ofensas a La Magd Sober ${ }^{\text {na }}$ y q en prueba de ello, haviendose el retirado del camino hacia dha Guard ${ }^{a} \mathrm{p}^{\mathrm{a}}$ las func precisas de la natural $^{\text {za }}$ allo dos pers $^{\text {as }}$ de distinto sexo infraganti (AGN, CGF, IX, I-7-3, 2 de septiembre de 1796. Énfasis con subraya en el original)

De este modo, se reconoce que dicha guardia ha tenido por lo menos dos ubicaciones (la actual y la "vieja”). Ahora bien, si esta guarnición muda su estructura y se infiere que está reducida a un rancho, puede suponerse que, en algunas de esas menciones, el uso de la palabra guardia se refiera más al lugar donde se monta vigilancia y menos a la estructura militar. En I790, la detención de un sospechoso de asesinato motivaba una solicitud de refuerzos para su traslado, y se explicitaba: "se sirva embiarlos con la posible brevedad, a fin de excusar el riesgo en $\mathrm{q}[\mathrm{u}] \mathrm{e}$ estamos de q[u]e los $\mathrm{d}[\mathrm{ic}]$ hos sus Par[ien]tes y Am[ig]os lo saquen y quiten, del rancho q[u]e sirve de guardia" (AGN, CGF, IX, I-7-3, 20 de enero de I790). Dos décadas antes, el propio comandante de la 
guardia de Las Conchas, para perseguir el contrabando en los puertos clandestinos, aseguraba: "Pondré al sargento con tres Dragones en San Ysidro, ínterin (si es que VS lo halla por comben[ien]te) se hace un Rancho q[u]e sirva de Guardia, en el paraje de los Olibos" (AGN, CGF, IX, I-7-2, II de agosto de I772). Claramente, estos ranchos que sirven de guardia extienden la polisemia del concepto y quizás se ajustarían mejor a la definición de "puesto de vigilancia".

Las dimensiones espaciales hacían difícil defender el territorio, tanto de las incursiones portuguesas como de las indígenas. Allí donde se ubicara una guardia, los "perseguidos" la evadirían hasta solidificar un paso nuevo, y la guardia debería mudarse o ponerse "un rancho que sirva de guardia". Este tipo de expresiones ponen en evidencia la polisemia de la palabra guardia, mientras que como estructura militar parece ser bastante endeble. Por otro lado, en 1767 , hacia el sur de la ciudad de Buenos Aires se produjo un conflicto entre el estanciero Noario y los soldados de tropa de la llamada "guardia avanzada", que se había asentado en su estancia desde hacía "algún tiempo". Con respecto a ello, Bartolomé Peredo explicaba: "convenia la separación deesta $\mathrm{Gu}$ [ardi]a al paraje señalado, como la 'Invernada de Juan Blanco"' (AGN, CGF, IX, I-5-2, I9 de diciembre de I767). Claramente, en este caso la acepción utilizada para guardia se ajusta al cuerpo de sujetos que guarda el lugar.

Estos corrimientos de las estructuras defensivas, deterioros paulatinos e instalación de nuevos emplazamientos avanzados implicaron la combinación del trabajo miliciano, blandengue, presidiarios y peones a jornal (Iraola, "Que no es servicio" 58-59). Todo ello significó, en cierto grado, una limitación, puesto que las posibilidades de realizar estas tareas estaban condicionadas por el número real de sujetos disponibles, las épocas del año y las problemáticas que suponían los espacios "ciegos" entre los pagos o lugares e incluso entre las propias guarniciones. Definitivamente, lo que permitía sostener los contactos entre las partes era una nutrida red de comunicación compuesta de chasques, partidas volantes y pobladores serviciales que pudieran llevar y traer noticias. Las guardias militares dotadas de personal (regular y miliciano) debían despachar partidas volantes que reconocieran el territorio, la presencia de indígenas, y lo informaran a sus superiores.

Dicha estructura defensiva fue montada entre los territorios de la Banda Oriental y Rio Grande do Sul, durante la ocupación española de este último (1763-I776). En abril de I764 los españoles arribaron a la villa de Río Grande de San Pedro, que no era más que un pequeño poblado mal defendido. Así lo informaba el comandante Joseph Molina a sus superiores: 
El terreno de la villa es de arena, como igualmente el de su entrada desde dos leguas. Ay una mediana Yglesia, dos almacenes y cuatro casas de teja, las demás casas son cubiertas de paja y formadas por paredes de madera ligadas con fajas de palma, cubiertas de barro, pero en lo interior están cubiertas con aseo. No ay en ella más fortificación que una bateria que defiende el canal que entra al puerto. (AGN, $R G$, IX-I6-5-5, I6 de septiembre de 1766)

Las guardias y puestos de frontera que los españoles fueron levantando para sostener estos territorios eran las más de las veces de "palo a pique" y normalmente guarnecían a poca gente. Podían contar con dos, ocho o diez hombres, dependiendo de los objetivos y de la ubicación. Así, las guardias denominadas de la "Boca del Río", compuestas por unos pocos hombres, sobre unas balandras, oficiaban de barrera a la entrada de la laguna y tenían la orden de "no permitir salir, o entrar en el río embarcación extranjera ni ninguna otra sin licencia, y de dar pronto aviso si se descubriese alguna embarcación en el Mar" (AGN, $R G$, IX-16-5-5, I6 de septiembre de I766). Claramente, estas guardias hacían referencia a la acción protectora más que a la estructura militar.

Por el contrario, las guardias de las estancias de caballadas del rey podían albergar hasta cincuenta hombres en época de guerra, como la guardia de Norte de la Laguna. La mayor o menor presencia militar en cada uno de esos espacios estaba determinada por la cercanía con el enemigo, así como por la posibilidad real de defender desde ese lugar la posición. Así, algunas de estas guardias servían para evitar el paso de los portugueses por el norte y vigilar sus movimientos (guardia de la Laguna); otras para verificar la entrada y la salida de la villa (guardia de la Boca del Río); para contener deserción (guardias del Tesorero y de San Gonzalo); y otras como postas intermedias de San Miguel hasta Santa Teresa, y de ahí a Maldonado para comunicarse con Buenos Aires:

A estos fines de resguardar el ganado de los terrenos de S. M. C, y contener la deserción mantiene la guardia del Tesorero dos guardias en la línea. La del puesto principal mantiene una de Dragones por el día, para contener la deserción y dos de noche que rodean los medanos de la circunferencia para el mismo fin de evitar deserción y resguardar aquel puesto de sorpresa. La guardia del Tesorero tiene la orden de retirarse al Puesto principal en caso de invasión de los portugueses [...] El terreno en el citado puesto principal, en aquella vanda es inepto para fortificarlo, de suerte que pueda defenderse largo tiempo, de numero capaz de 
ocupar y mantener los medanos de arena de la circunferencia, porque en ellos pueden cubrirse medianamente los asediantes del fuego de las baterías, por cuio motibo solo pueden servir las defensas construidas en el para contrarestar un golpe de mano, y mantenerlo algún tiempo a dar lugar a recivir socorro. (AGN, $R G$, IX, I6-5-5, I6 de septiembre de I766)

Como se puede observar en el citado informe del comandante Molina, las guardias y puestos de frontera que se encontraban en las inmediaciones de la laguna de Los Patos eran generalmente de reducidas dimensiones y materiales de construcción endebles. Esto debía ser necesariamente así por la geografía del terreno que acarreaba "el inconveniente, de que solo se puede trabajar de Palo a pique, y los medanos de arena a poco tiempo lo han de cubrir, por lo que será gastar el dinero superfluamente" (AGN, BO-FST, IX-I5-8-I, 27 de agosto de 1769). Por este motivo, se diseñó un sistema de postas defensivas en el que cada una resistiría solamente lo necesario. De acuerdo con el número de atacantes, defenderían la posición o retrocederían en la medida de la correlación de fuerzas. Los puntos estratégicos en este sistema serían, lógicamente, los fuertes y las fortalezas artilladas, desde donde se resistiría una invasión enemiga en mejores condiciones.

Luego del Tratado de Límites de $\mathbf{1 7 7 7}$, la zona de Melo, al norte de la Cuchilla Grande, cobró relevancia por la cercanía con la nueva frontera y con los pueblos guaraníes de las antiguas misiones jesuitas. El comandante de Frontera de la guardia de Cerro Largo vigilaba siete guardias, una estancia del rey y varios puestos de frontera, desde Batoví hasta Minas y el Chuy (AGNU, CP-PD, I792).

Entonces, la guardia de Cerro Largo inició siendo una modesta construcción de fajina, tepes y palo a pique, comparable a las guardias bonaerenses. No obstante, hacia fines del periodo colonial, al convertirse en comandancia, su construcción pasaría a ser de piedra, aunque sin baluartes, pero conservaría la denominación de guardia. Consideramos que fue así, porque en una frontera móvil, con múltiples frentes de conflictos y de negociaciones con los diferentes pueblos indígenas, tanto como con los contrabandistas portugueses, no había una línea de frontera que defender y sobre la que avanzar paulatinamente, sino más bien modestas construcciones o lugares desde donde intentaron controlar la frontera

Para la construcción de tres importantes puestos o guardias mandado de Real Ordn he comisionado al alférez de Fragata y piloto de la Real Armada $\mathrm{D}^{\mathrm{n}}$ Joaquin Gudin, $\mathrm{q}^{\mathrm{e}}$ recorrio y reconicio los parages en qe deben situarse. Lo q $\mathrm{q}^{\mathrm{e}}$ prevengo a V.M Pa que le franquee los auxilios que 
le pida como necesarios para evacuar este encargo. (AGNU, $C P-P D$, 2I de noviembre de I792. Énfasis con cursiva ańadido)

El pedido del virrey Arredondo al comandante de Santa Teresa fue remitido a su par de Cerro Largo, pidiendo que se auxiliara a los comisionados que recorrían la frontera para saber en qué lugares establecer las nuevas guardias o mudar las ya existentes. Este traslado estaba determinado tanto por la movilidad de los indígenas charrúas y minuanos como por los diferentes caminos que iban estableciendo los gauderios, forasteros y demás contrabandistas a ambos lados de la frontera que se pretendía controlar. En ocasiones, guardias y puestos designaban un lugar y una función castrense, a saber, estar de guardia en tal o cual lugar, de modo tal que una guardia de frontera, entonces, podía ser una carreta, como informa Nicolás Senet en el caso de la frontera bonaerense:

Cuando llegue â establecer mi residencia en este parage lo encontré tan exausto de aloxamiento $\mathrm{q}^{\mathrm{e}}$ no tube mas efuxio pa mi abitacion $\mathrm{q}^{\mathrm{e}} \mathrm{un}$ descipto carreton Lleno de mil sabandijas y unos pequeńos arboles $\mathrm{p}^{\mathrm{a}}$ la colocación y acomodo de Un sarg ${ }^{\text {to }}$ Cavo y ocho ombres $q^{\mathrm{e}}$ componían mi partida y Ningunos caballos a mi disposición $\mathrm{p}^{\mathrm{a}}$ exercer la comisión a $\mathrm{q}^{\mathrm{e}}$ estaba destinado. (AGN, CGF, IX-I-4-4, I. ${ }^{\circ}$ de octubre de 1773 )

La guardia, no obstante, también se podía cumplir en algún puesto de estancia - misioneras o particulares-, en una balandra o una corsaria sobre la laguna Mirim, para controlar el contrabando por los ríos y arroyos afluentes (AGNU, CP-PD, I8 de diciembre de I796), mientras que en Buenos Aires sabemos que podía referirse a los sujetos que realizaban las partidas volantes, como era el caso de la orden de Manuel Pinazo sobre que "pide se saquen las guardias afuera" (AGN, CGF, IX-I-4-4, 20 de abril de I779). Del mismo modo, una guardia se refería, en la Banda Oriental, a modestas construcciones sobre un río importante para controlar su paso, como era el caso de las guardias de Yaguarón, Santa Rosa, San Antonio y San José, que contaban con no más de cinco hombres por guardia (AGNU, $C P-P D, 2$ de enero de I792).

Por último, podemos mencionar los rutinarios informes emitidos por la guardia de Ensenada - Buenos Aires - sobre el control y la administración de las embarcaciones extranjeras recaladas a su vista. Estos informes dejaban en evidencia que la guardia de Ensenada, ubicada de frente al mar, provista de una batería y un almacén de pólvora (algo propio de los fuertes), tenía una pequeña guarnición que en su mayoría eran milicianos y artilleros, mientras comandaban 
los puestos de control de Punta Lara y la desembocadura del arroyo Villoldo y "La Balandra", a la vez que montaban guardia en la lancha de Joseph de Salas, la fragata Venus y unos botecillos en los arroyos Santiago y de las Curvas (AgN, $C G F$, IX-I-5-I). Así mismo, las guarniciones de La Atalaya y Samborombón informaban avistamientos de embarcaciones a Ensenada, mientras que los informes se firmaban desde la guardia.

\section{Consideraciones finales}

En este escrito, la propuesta consiste en reconocer de manera general y exploratoria algunas de las características de las estructuras militares en el espacio rioplatense, comparando los emplazamientos de la Banda Oriental con aquellos de la frontera bonaerense, para identificar funciones, conflictos y necesidades.

En este sentido, se ha podido advertir, en un primer momento, que las fortificaciones abaluartadas de tipo Vauban fueron la excepción más que la regla. Tanto por la necesidad geopolítica como por los recursos económicos y los problemas de logística que implicaba su construcción, solo se erigieron en los lugares estratégicos. En el espacio bonaerense, la carencia de piedras, como también de recursos materiales, llevó a que el fuerte de Buenos Aires fuera erigido con los tradicionales ladrillos de adobe cocidos al sol. Aunque el diseño estructural fuera similar a los del litoral atlántico, que incluían la construcción amurallada y la forma estrellada con baluartes, no estaba preparado para resistir la invasión de una potencia extranjera. Por su parte, en los fuertes y fortines de la frontera bonaerense no solo se destacan los adobes como elemento constructivo, sino que la madera tiene una presencia notoria, con un uso selectivo de estas. No obstante, se destaca en algunos casos la presencia de piedras, sobre un lado, combinadas con palos sobre el otro lado.

A partir de la documentación colonial, se observa que la designación de fuerte a una estructura militar no se encuentra necesariamente ligada a sus aspectos constructivos. Si para la Banda Oriental la designación de fuerte o fortaleza solo hace referencia a los castillos militares abaluartados, en la frontera bonaerense puede aludir indistintamente a un fortín o una guardia y viceversa, lo que lleva a pensar que la historiografía ha estereotipado las palabras fuertes, fortines y guardias como tipologías fijas, a pesar de que la documentación pone en evidencia un considerable dinamismo. 
En cuanto a las designaciones de puestos y guardias de frontera, por un lado, la historiografía colonial rioplatense ha tendido a homogeneizar la idea de las construcciones militares de palo a pique para los fortines, y ha extendido esta característica a todas las guardias o puestos, sin reparar en la necesaria movilidad de dichas estructuras defensivas, mientras que, por otro lado, la polisemia de la palabra guardia ha llevado a la confusión entre diferentes conceptos que se utilizaban en la época para nombrar tanto los emplazamientos defensivos como las personas que cumplían una función castrense. De este modo, la sola mención en las fuentes documentales de la existencia de una guardia exige un relevamiento seriado del material, a los fines de precisar si se refiere a la acción de montar guardia o a la existencia de una estructura militar.

Los relevamientos documentales contribuyen a nuestro enriquecimiento de las características genuinas de construcción y dotación de fuerzas castrenses para propender a la reconstrucción de una historia geopolítica que evalúe un conjunto de variables mayor, pero que también ponga un análisis en perspectiva dinámica. De este modo, se podrá comprender de manera más certera los pormenores del control del espacio y las estrategias militares de ocupación y consolidación de ese mismo espacio. En futuros estudios será necesario precisar la historicidad de los puestos, de los guardas y las guardias, para con ello contribuir a seguir disipando los problemas de la polisemia de los términos.

\section{. \\ $\begin{array}{llllllllllll}\text { B I } & B & L & I & \mathbf{O} & G & \mathbf{R} & \mathbf{A} & \mathbf{F} & \mathbf{I} & A\end{array}$}

\section{F U E N T ES PR I M A R A S}

\section{A. Archivos}

Archivo General de la Nación, Buenos Aires, Argentina (AGN).

Fondo Comandancia General de Fronteras (CGF)

IX, I-4-4; I-5-I; I-5-2; I-7-2; I-7-3; I-5-3; I-4-I; I-7-4.

Fondo Río Grande $(R G)$

IX, I6-5-5.

Fondo Banda Oriental, Fortaleza de Santa Teresa (BO-FST)

IX, I5-8-I.

IX, I5-8-2. 


\section{Archivo General de la Nación, Montevideo, Uruguay (AGNU). Fondo Colecciones Privadas-Pivel Devoto $(C P-P D)$.}

\section{I. F U E N T ES SECUNDARIAS}

Aguirre, Andrés. "Conflictos interétnicos en la frontera sur hispano-portuguesa. El caso de Río Grande de San Pedro durante la ocupación española de 1762-1777". Revista Tefros, vol. I2, n. ${ }^{\circ}$ I, 2014 , pp. 6-25, http://www2.hum.unrc.edu.ar/ojs/index.php/ tefros/article/view/273

Barros, Álvaro. Indios, fronteras, seguridad interior. Buenos Aires: Solar/Hachette, 1975.

Beverina, Juan. El Virreinato del Río de la Plata. Su organización militar. Buenos Aires: Biblioteca del Oficial, 1992.

Cabodi, Juan. "Historia de la ciudad de Rojas hasta 1784 . El fuerte de la Horqueta de Rojas y la guardia de Rojas (1779)". Contribución de la Historia de los Pueblos de la Provincia de Buenos Aires, tomo xxvir. Provincia de Buenos Aires: Archivo Histórico de la Provincia de Buenos Aires, 1950, s. p.

Canedo, Mariana. "Fortines y pueblos en el Buenos Aires del siglo Xviri. ¿Una política de urbanización para la frontera?". Mundo Agrario-Revista de Estudios Rurales, vol. 7 , n. ${ }^{\mathrm{I}}$ 13, 2006, pp. 7-18, www.mundoagrario.unlp.edu.ar.

Covarrubias Orozco, Sebastián de. Tesoro de la lengua castellana o española. I7io. Madrid: Castellana, 2002.

Fradkin, Raúl. “Tradiciones militares coloniales. El Río de la Plata antes de la Revolución”. Experiências nacionais, temas transversais: subsidios para uma história comparada da América Latina. São Leopoldo: Editora Oikos, 2009, pp. 74-ı26.

Garavaglia, Juan. "Ejército y milicias: los campesinos bonaerenses y el peso de las exigencias militares, I810-I860". Anuario IEHS, vol. 18, 2003, pp. I53-187.

Gascón, Margarita. Periferias imperiales y fronteras coloniales en Hispanoamérica. Buenos Aires: Editorial Dunken, 201 .

Gillespie, Alexander. Buenos Aires y el interior. Observaciones reunidas durante una larga residencia, I806-1807. Buenos Aires: AZ Editorial, 1994.

Gutiérrez, Ramón. Fortificaciones en Iberoamérica. Madrid: Fundación Iberdrola, 2005.

Halperín Donghi, Tulio. Militarización revolucionaria en Buenos Aires. Buenos Aires: UBA, 1978.

---. Revolución y guerra. Formación de la elite dirigente en la Argentina criolla. 1972. Buenos Aires: Siglo XXI, 2005. 
Iraola, Eduardo. "Que no es servicio del Rey. Milicias y trabajo en obras públicas. Buenos Aires (1750-1800)". Trashumante. Revista Americana de Historia Social, n. ${ }^{\circ}$ 1 4, 2019, pp. 76-98, DOI: I0.17533/udea.trahs.ni 4aO3

--.. “Los trabajos en la reparación del Puente del Río Luján”. I Jornadas de Estudios Coloniales, Universidad Nacional de Villa María, 2013.

Luzuriaga, Juan. “Campañas de Cevallos y fortificaciones, 1762-1777”. IV Seminario Regional de Ciudades Fortificadas, 2008, http://www.fortalezas.ufsc.br/6seminario/index.php.

--.. "El sistema de fortificaciones en la Banda Oriental: Montevideo, Santa Teresa, San Miguel y Santa Tecla: 1762-1777”. VI Seminario Regional de Cidades Fortificadas e Primeiro Encontro Técnico de Gestores de Fortificações, 2010, http://www.fortalezas. ufsc.br/6seminario/index.php

Marchena Fernández, Juan. "El ejército de América y la descomposiciñon del orden colonial. La otra mirada en un conflicto de lealtades". Militaria. Revista de Cultura Militar, n. ${ }^{\circ}$ 4, 1992, pp. 63-92.

Mayo, Carlos y Analía Latrubesse. Terratenientes, soldados y cautivos: la frontera, 1736 -I8I5. Mar del Plata: Universidad Nacional de Mar del Plata, 1993.

Nacuzzi, Lidia. "Los caciques amigos y los espacios de la frontera sur de Buenos Aires en el Siglo XVIII”. Revista TEFROS, vol. I2, n. ${ }^{\circ}$ 2, 2014 , pp. I03-139, http://www2.hum.unrc. edu.ar/ojs/index.php/tefros/issue/view/23/showToc.

Nacuzzi, Lidia, Carina Lucaioli y Florencia Nesis. Pueblos nómades en un estado colonial. Chaco, Pampa, Patagonia, siglo XVIII. Buenos Aires: Antropofagia, 2008.

Néspolo, Eugenia. “Cautivos, ponchos y maíz. Trueque y compraventa 'doble coincidencia de necesidades' entre vecinos e indios en la frontera Bonaerense. Los pagos de Luján en el siglo XVIII". Estudios de arqueología histórica. Investigaciones argentinas pluridisciplinarias, editado por Tapia-Ramos-Baldassarre. Tierra del Fuego: Museo de la ciudad de Río Grande, 2006, pp. 379-402.

--.. Resistencia y complementariedad. Gobernar en Buenos Aires. Luján en el siglo XVIII: Un espacio politicamente concertado. Buenos Aires: Escaramujo, 2012.

Pérez Jurado, Carlos. "Las milicias en la primera república”. Boletín de la Academia Nacional de la Historia, vol. LXVII, n. ${ }^{\circ}$ 268, pp. 793-803.

Raone, Juan. Fortines del desierto. Mojones de civilización. Buenos Aires: Biblioteca del Suboficial, 1969 .

Tamagnini, Marcela. "Entre los salvajes unitarios y los bárbaros del sur: la Frontera Sur de Córdoba en la década de 1840 ”. Araucanía-Norpatagonia. Discursos y representaciones de la materialidad, compilado por María Andrea Nicoletti, Paula Ilabaca y Andrés Núñez. Bariloche, Argentina: Universidad Nacional de Río Negro, 2016, pp. 37 I-390. 